\title{
PARAMETRIC APPROACH FOR GENERATING NEW MUQARNAS
}

Received July 20th 2018 | Accepted October 11th 2018 | Available online June 30th 2019 |

DOI http://dx. doi. org/10.18860/jia.v5i3.5322

\section{Sherif Zeid}

Faculty of Engineering,

Alexandria University

Alexandria, Egypt

sherifusa1988@yahoo.com

\section{Ibrahim Maarouf}

Faculty of Engineering

Alexandria University

Alexandria, Egypt

Ibrahim.maarouf@alexu.edu.eg

\begin{abstract}
In recent decades, the search for new geometrical innovations has been of great interest for contemporary architects \& artists, trying to escape the repetitive use of historical ornamental details of architectural styles \& orders or the absence of such ornaments in the modern style. This paper aims to lay down the basis for generating new muqarnas elements based on the cosmological nature of Islamic Architecture, but still preserving its concepts. The muqarnas was chosen because it is one of most original inventions of Islamic architecture and one of its most effective and widespread applications. Innovation in its design requires freedom of expression that can be limited by design software. Furthermore, the process of testing ideas can be tedious and time-consuming. Parametric and generative design, using Grasshopper, is used to reformulate the muqarnas generation process using visual programming. Parametric design and hypothetical geometric patterns in a linear or polar arraying direction produce a clearly defined muqarnas.
\end{abstract}

KEYWORDS:

Islamic Architecture; Muqarnas; Parametric; Algorithmic; Grasshopper

\section{INTRODUCTION}

Islamic art and architecture are characterised by decoration and repetition. The primary role of Islamic decorations is characterizing Islamic Architecture and giving its structures a unique and authentic style. Muqarnas is considered one of the most original, effective, and widespread inventions of Islamic architecture [1] [2].

Muqarnas is the Arabic word for stalactite vault; a captivating structure based on replicating units arranged in tiers, each one supporting another corbel on top of it [3] (Figure 1). The use of muqarnas in buildings flourished in several Islamic countries since the $8^{\text {th }}$ century such as; Baghdad, Iran, Egypt and Syria, where new designs and different uses for it was found in each region as the years progressed. Innovations in the design of muqarnas deteriorated, however, since the fall of the Ottoman Empire.

Recently, at the start of the $21^{\text {st }}$ century, the tremendous advances in computer technologies provided the tools for architects and artists alike to generate contemporary highly complex forms and shapes that can be used as building forms or ornaments or for various other uses.

This paper intends to use such tools to lay a foundation for the generation of new muqarnas designs using algorithmic and parametric design while ensuring the preservation of the cosmological nature of Islamic architecture used in the ornaments found in historic Islamic buildings.

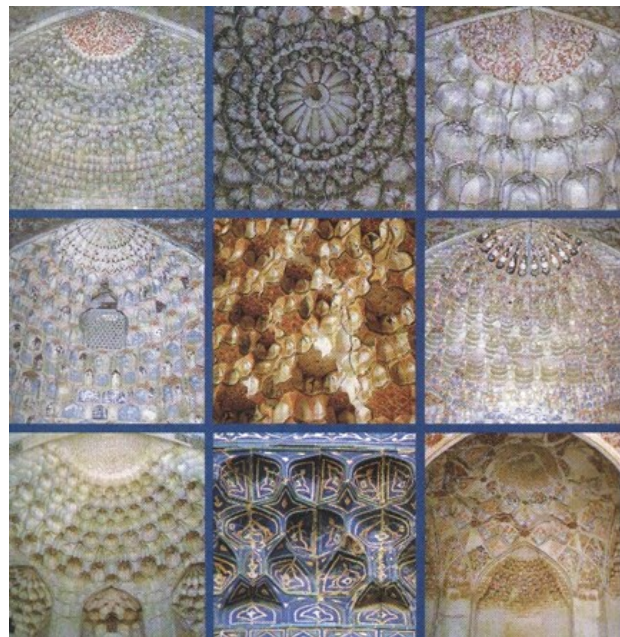

Figure 1. Different examples of applications of muqarnas [4]

This paper intends to use such tools to lay a foundation for the generation of new muqarnas designs using algorithmic and parametric design while ensuring the preservation of the cosmological nature of Islamic architecture used in the ornaments found in historic Islamic buildings.

\section{ISLAMIC ARCHITECTURE}

Islamic architecture incorporated a massive array of diverse styles throughout its 1400 year long history. 
Its form was influenced by the architectural styles of Roman, Byzantine, Persian, Indian, and Chinese architectures due to the wide-spread of Islam from North Africa to East Asia and parts of Europe [5].

The Islamic architecture foundations were created based on the principal balance of nature mixed with several geometrical theories relating perfect proportions and symbolic implications. The designers found their geometrical vocabulary on what was observed in the environment surrounding them, in an attempt to develop a codified series of proportions which may improve our psychological comfort with buildings [6].

The Islamic art designers favoured geometry due to its intelligible aspect. Geometry is characterized by abstraction and the capacity to convey and expose objectively immutable and spiritual truths. Geometry represents the proportions of beauty which, for Muslim artists, is the interpretation of objectivity, which is considered the fundamental nature of beauty [7].

\section{ISLAMIC GEOMETRICAL PATTERNS}

In Islamic art, geometric elements have been employed since its birth and were used to create unique geometric formations, serving as the underlying structure of the Islamic designing process.

Geometry is an original and significant part of Islamic art and architecture. It is the visual means by which the human mind can comprehend the order and harmony inherited in the Creation. Furthermore, it is considered to be the visual representation of the mathematical patterns found everywhere in man, nature, and the universe. These patterns, with their artistic and philosophical values, are included in all prospects of Islamic architecture [8].

Islamic geometric patterns have been used for centuries as ornaments on walls, ceilings, doors, and domes. However, the lack of guidelines and codes for applying these ornaments often leads to inappropriate use in terms of time scale accuracy and architectural style.

\section{ISLAMIC ORNAMENTS}

Islamic art and architecture are characterised by decoration and repetition [9]. The extent to which a form has an architectural and decorative function helps determine its total value in an Islamic context to the degree that is unknown to Western aesthetics. For Western art and architecture. On the contrary, in Islamic architecture, these two components are inseparable.

That being said, these essential components of Islamic decoration aren't just for characterizing purposes, but also have a philosophical and sociological dimension. To further elaborate, the numbers were divine, for a Pythagorean, and understanding the relationships between them can only lead to comprehending the essence of the universe [10].

Islamic geometric decorations can be categorized into two major categories: two dimensional and threedimensional patterns [11]. The star pattern is a relative- ly famous example of this category. The second category is the muqarnas, which is a $3 \mathrm{D}$ ornamental structure.

\section{MUQARNAS}

As stated before, Muqarnas is a $3 \mathrm{D}$ ornamental structure unique to Islamic architecture; it is as much a component of the vernacular of Islamic architecture as the Ionic column is of Greco-Roman architecture [12]. Its purpose is to provide a transition between, for example, a square base and a dome or just a wall and ceiling.

Different regions in the Islamic world have used different styles of construction techniques in their history. Some have decorated the tiles; some have left them uncoated for the sole purpose of highlighting the muqarnas and creating mesmerising effects with light and shadows (Figure 2).

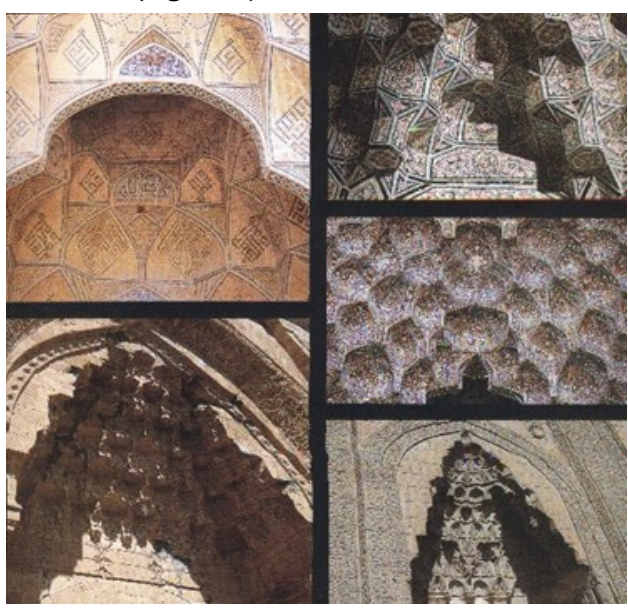

Figure 2. Different Styles of Muqarnas [4]

Muqarnas compositions could be used in contemporary architecture. The combination of concave and convex surfaces could be applied in many scales, from tiles to larger building components, as demonstrated in some of the works of Jørn Utzon.

\section{ORIGINS}

The Muqarnas was developed in the tenth century in both North-Eastern Iran and Central North Africa, two ends of the sprawling stretch of the Islamic empire. It became a prominent feature in almost all of the Islamic structures of the eleventh century and onwards, and remained a vital element of the Islamic architectural vernacular until modern times.

\section{STRUCTURE}

There are four main characteristics of the muqarnas that distinguish its appearance. Firstly, it is three-dimensional, thereby providing volume in built structures. Secondly, the degree of its size is variable; this variability resulted in compelling architects to realize the muqarnas either as an architectonic intended to 
provide support to a structure or as an ornamental decorative element. Thirdly, the muqarnas has no exact mathematical boundaries; this is due to varying sizes of its cells as a result of the transitional role that the muqarnas performs either between different levels, shapes or sizes. Taking that into consideration, perhaps it is useful to compare the layered honeycomb patterns of the muqarnas to a figure such as the fractal. The fractal, a geometric figure which is defined by a simple algebraic equation, also knows no limitations or boundaries and can conceivably stretch to infinity. Finally, the fourth characteristic of the muqarnas is that, because of its variable volume, a 3D unit can easily be converted into a two-dimensional figure called a 2DPP (2-dimensional pattern plan).

Even though the muqarnas is of intricate complexity, its form is defined by constant rules dictating the relationships between its components. It can be further seen in the definition of the muqarnas given by the fifteenth century Timurid mathematician Al-Kashi (1380-1429):

"The muqarnas is a ceiling like a staircase with facets and a flat roof. Every facet intersects the adjacent one at either a right angle, or half a right angle, or their sum, or another combination of these two. The two facets can be thought of as standing on a plane parallel to the horizon. Above them is built either a flat surface, not parallel to the horizon, or two surfaces, either flat or curved, that constitute their roof. Both facets, together with their roof, are called one cell (Figure 3). These cells are arranged in horizontal courses, as in a corbelled vault, with the horizontal joint surface having a different shape at each level." [13]



a

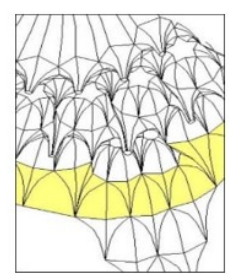

b
Figure 3. (a) A muqarnas cell (b) Cells arranged in horizontal courses [14]

Al-Kashi uses geometric terms, indicating that the muqarnas is the space in which a particular mathematical problem is enacted. In this problem, the possible number of permutations is determined by variations on the $90^{\circ}$ angle. As al-Kashi indicates, the angle at which two facets intersect can be any conceivable angle, as long as it corresponds to "a right angle, or half a right angle, or their sum, or another combination of these two." [15].

\section{CONSTRUCTION METHODS}

An essential aspect of understanding the structural nature of the muqarnas is to understand their construction methods. Muqarnas are typically constructed in three ways: corbeled, superimposed and suspended. A corbeled muqarnas is a solid structure built from stone or wooden blocks. Muqarnas cells are carved outwards from the middle of the block face, either before or after assembling (Figure 4a). The supporting surface is built first (for example a dome or vault) to create a superimposed muqarnas. Then muqarnas elements are built up against concave surfaces, leaving no hollow space between the muqarnas and the supporting surface (Figure $4 \mathrm{~b}$ ). A suspended muqarnas is an assembly of surface-decorated panels. The panel components are produced on the ground, then combined and fixed to the architectural structure using attachment ribs, this method is characterized by a space between the muqarnas shell and the structure (Figure 4c) [16].

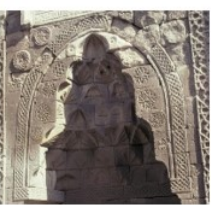



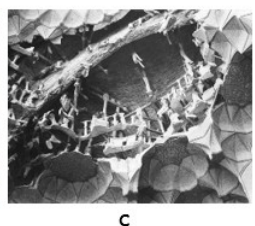

Figure 4. (a) Corbeled muqarnas (b) Superimposed muqarnas (c) Suspended muqarnas in the process of repair. Attachment ribs and empty spaces between the muqarnas surface and the walls are visible [16]

\section{ALGORITHMIC \& PARAMETRIC DESIGN}

Whether it is referred to as Parametric Design, Generative Modeling, or Computational Design, it provided architects and designers with a freedom of expression and made the process of testing ideas less tedious and time-consuming. As a result, making wildly complex patterns with numerous iterations to find the best and most efficient outcome has become accessible to the universal architect.

\section{VISUAL PROGRAMMING}

Visual Programming is a paradigm of computer programming within which the user manipulates logic elements graphically instead of textually. Some of the most well-known textual programming languages such as C\#, Visual Basic, Python and Rhinoscript require a code to be written that is bound by language-specific syntax. In contrast, visual programming allows us to connect functional blocks into a sequence of actions where the only "syntax" required is that the inputs of the blocks receive the data of the appropriate type (Figure 5), and ideally, that is organized according to the desired result.

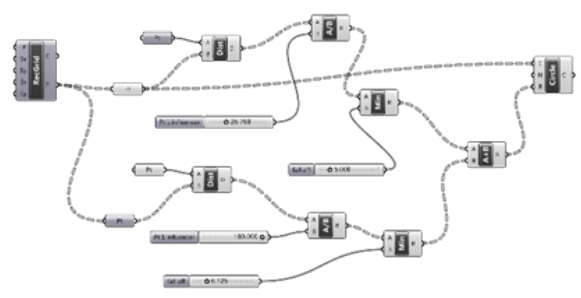

Figure 5. A node diagram from the software extension in Rhino called Grasshopper [17] 


\section{NEW MUQARNAS}

Using this powerful tool (visual programming) in the generative process of designing a new muqarnas can lead to several methods which could be used as the base for the concept of design. The method that was chosen in this paper is an old original Islamic pattern concept known as "Magic Squares".

\section{MAGIC SQUARES}

"Magic squares are conspicuous instances of the intrinsic harmony of the number, and so they will serve as an interpreter of the cosmic order that dominates all existence. They appear to betray some hidden intelligence which by a preconceived plan produces the impression of intentional design." [18]

The above sentiments were those of Paul Carus in his foreword to W. S. Andrews' life work on Magic Squares first published in 1917. The attitude would not be so very different from the traditional Islamic one. The actual difference, however, is firstly the undoubted Divine origin to mathematics. Secondly, the qualitative aspect of number (of which magic squares are an example) is given greater significance, and therefore metaphysical effectiveness, than the merely quantitative. Therefore, as the expression of archetypal entities, numbers are far more than the 'mere intellectual play' of Carus as they not only sustain but pervade the form of the terrestrial elements quite in harmony with the findings of modern physics. Through this latter fact, they can be useful in the scheme of things and represent a branch of science in themselves [19].

In our case, we are concerned primarily with the concept of magic squares, and as there are many different iterations of magic square patterns, for the sake of abbreviation, the $3 \times 3$ square of Saturn (Figure 6 ) will be used, as it's one of the most basic and easy to comprehend magic square patterns. However, using the methodology of generation presented in this paper is not limited to just this type of magic square pattern, and that is one of the perks of using parametric and algorithmic design, which is the flexible nature of applying new concepts and achieving different results almost instantly.

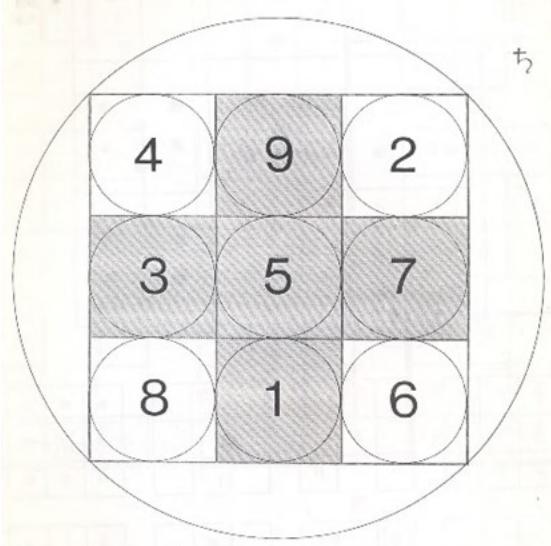

Figure 6. 3×3 square of Saturn [19]
As illustrated, a $3 \times 3$ square of Saturn archetype, showing in tone the symmetry between odd and even numbers. There are eight possible ways of arranging the outer numbers around the central figure " 5 ".

The figure below describes the method of arranging the numbers in sequence graphically, the digits from 1 to 9 are placed in three diagonal lines; this results in five digits within the square $(2,4,5,6$ and 8$)$, the others being outside it. Then the curved lines demonstrate how these digits are rearranged to generate a possible pattern that still fulfils the rules of the $3 \times 3$ square of Saturn (Figure 7 ).
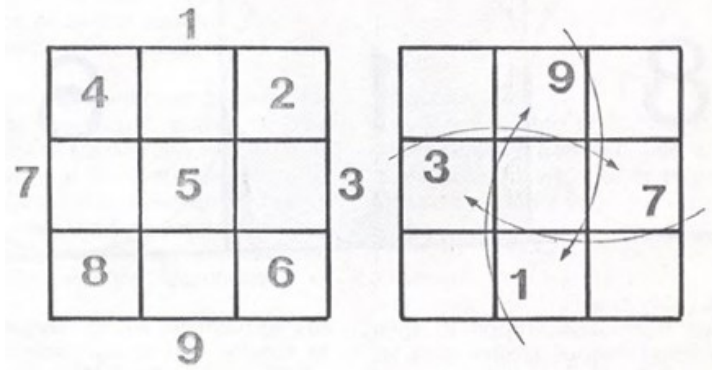

Figure 7. Rearrangement of odd digits in magic square [19]

\section{GENERATING A 2D ISLAMIC GEOMETRIC PATTERN}

Adopting this rearrangement method and applying it parametrically, to generate a geometric pattern would be the following step. But first, the outer perimeter of the square will be divided into vertices to aid this process and make implementing it in the parametric software (Grasshopper) easier (Figure 8).

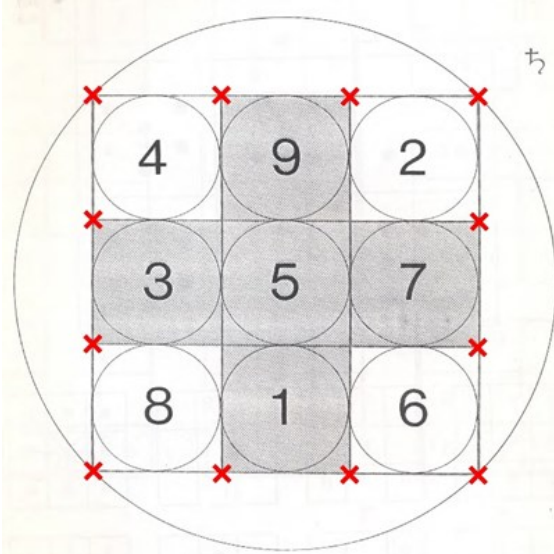

Figure 8. Placing vertices on the outer perimeter grid of the magic square [19]

Following that, an analogy of the magic square is created in Grasshopper. The perimeter vertices are numbered for explanatory purposes only. By emulating the rearrangement method of the magic square clarified before, diagonal connecting lines only between the vertices of the interchanging odd numbers are drawn (Figure 9). To clarify, the diagonal line between vertex 10 and 4 represent the movement of the number 3 to the grid of the number 7 , and the line between vertex 5 and 11 represent the movement of number 7 to replace number 3 in the magic square grid. 


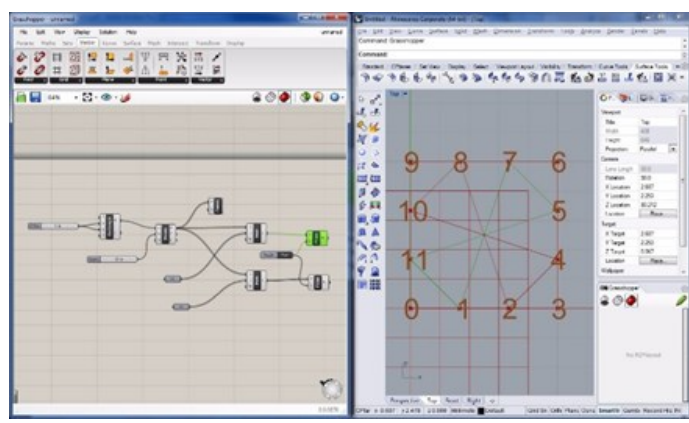

Figure 9. Generating pattern as an analogy of the rearrangement method of the magic square - Generated by the author from grasshopper

By arraying this pattern in a grid, a 2D geometric pattern is generated (Figure 10).

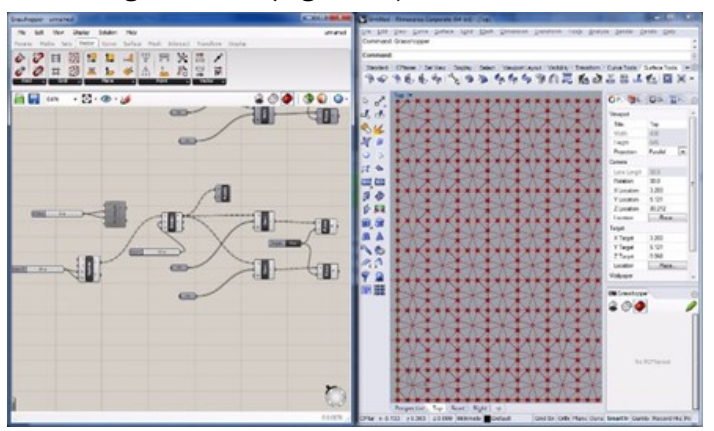

Figure 10. 2D geometric pattern achieved from the repetition process - Generated by the author from grasshopper

The 2D pattern is then extracted (Figure 11) to compare it to the basic patterns of the geometrical art patterns of Islamic Architecture found in "Arabic Geometrical Pattern and Design" by J. Bourgoin, and define which pattern it is similar to in its basic concept and tracing of lines and curves.

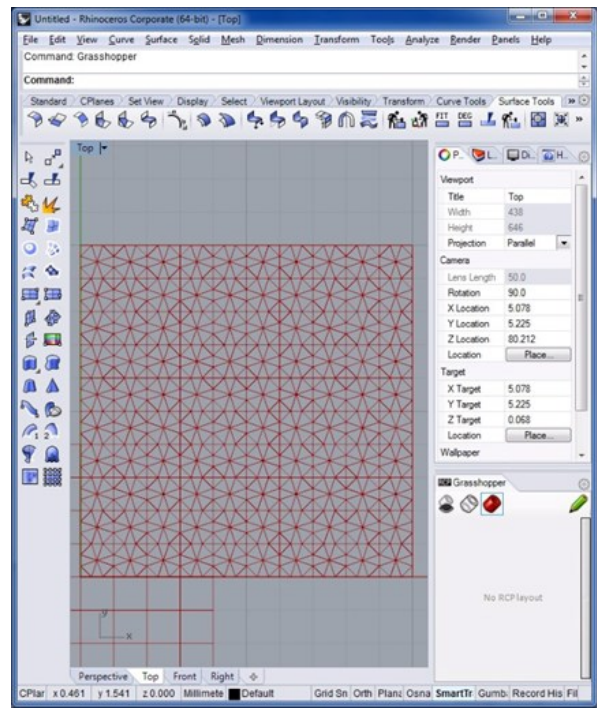

Figure 11. 2D geometric pattern achieved from the repetition process - Generated by the author from grasshopper

Consequently, two geometric patterns were chosen for the resemblance in the relationship be- tween the axis and the center point of the pattern (Figure 12), and this nominates the generated pattern to be considered an Islamic design.

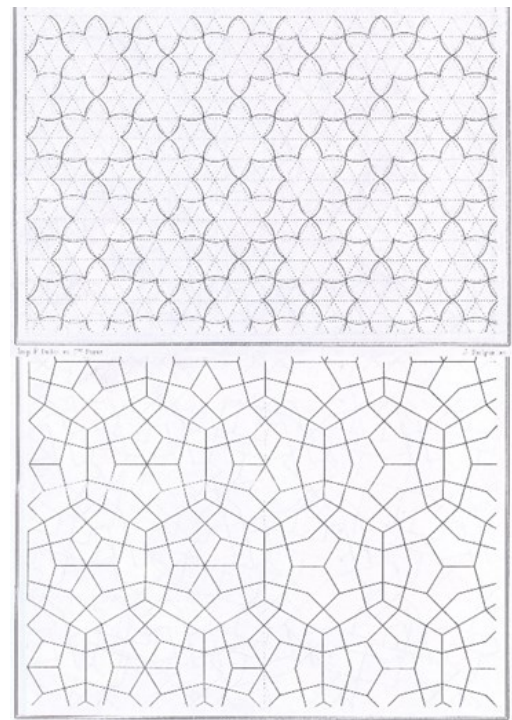

Figure 12. Islamic geometric patterns resembling the generated grasshopper in basic concept [20]

\section{TRANSFORMING THE 2D PATTERN INTO A 3D MUQARNAS}

Forming a 2D boundary to extrude (Figure 13) and use in the $3 \mathrm{D}$ modelling process would be the first step.

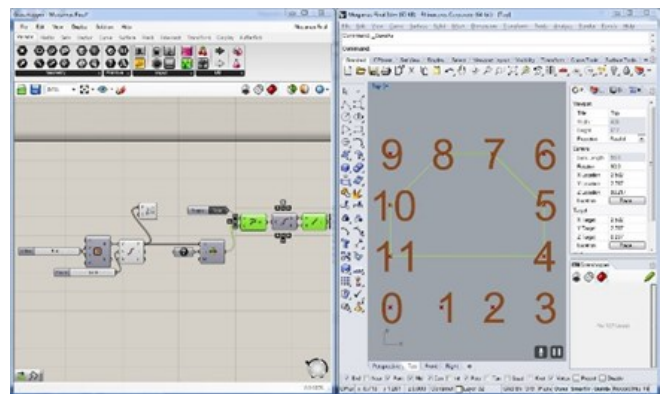

Figure 13. 2D edge created from the geometric pattern Generated by the author from grasshopper

Then, a model consisting of 2 parts is created; the first part is an extrusion of the boundary with a height $=\mathrm{H}$, and the second part is a cap with extrusion to the midpoint of the longest edge with a height $=1 / 2 \mathrm{H}$ (Figure 14).



Figure 14. 3D model extruded from the 2D boundary - Generated by the author from grasshopper 
The next step would be creating the muqarnas base unit that will be arrayed in a linear path to form a corniche for example, or even a polar array to be part of a dome. A cuboid is created with its dimensions relative to the model and the thickness intended for the muqarnas base unit (Figure 15). Following that, the two forms would be subtracted from each other to generate the muqarnas base unit (Figure 16), as it's considered a negative architectural element.

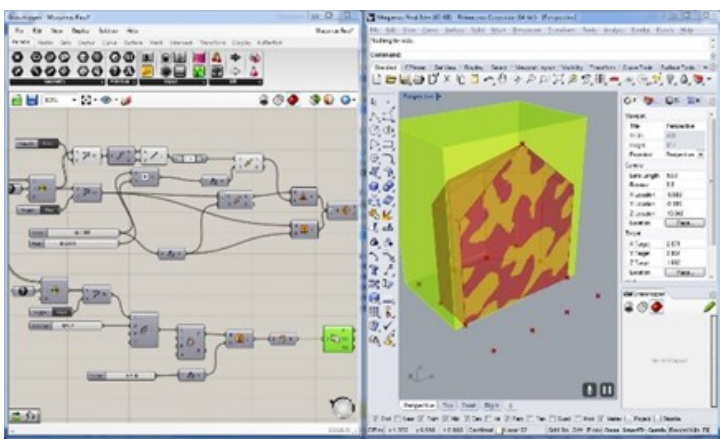

Figure 15. Cuboid to subtract the model from - Generated by the author from grasshopper

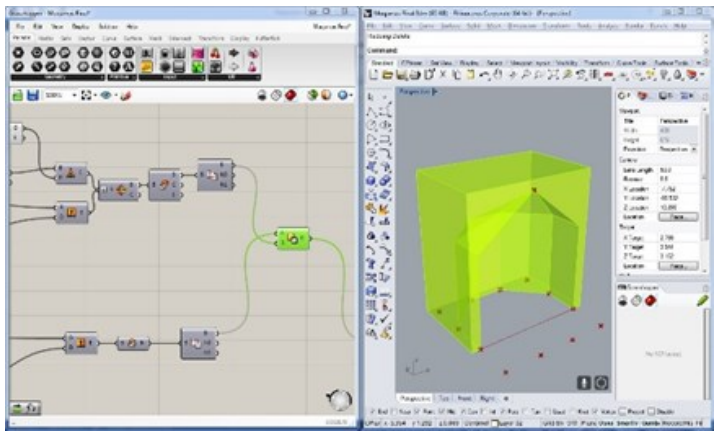

Figure 16. 3D Muqarnas base unit generated after subtraction - Generated by the author from grasshopper

\section{ARRAYING OF MUQARNAS BASE UNIT}

Before starting the array process, a solid trim by an inclination angle based on support system relation is performed on the muqarnas base unit (Figure 17), to ensure the muqarnas transition to be vertically stable.

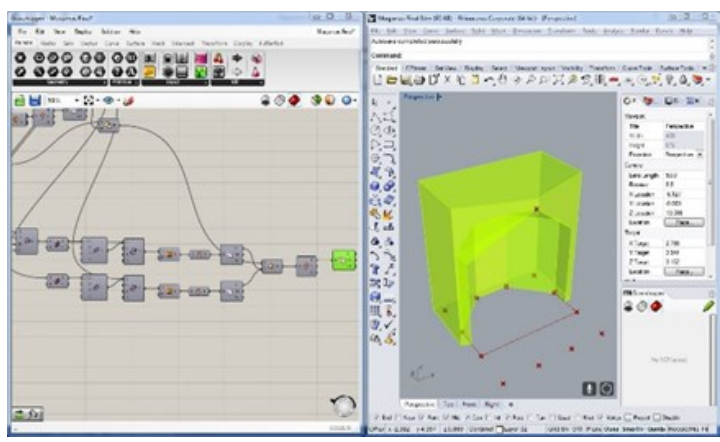

Figure 17. Solid trim to muqarnas base unit - Generated by the author from grasshopper
Using this grasshopper node diagram definition (Figure 18), the muqarnas base unit is arrayed linearly. Following that, the process is repeated but vertically and with a displacement of $1 / 4$ of the base unit's width to generate the upper row (Figure 19).

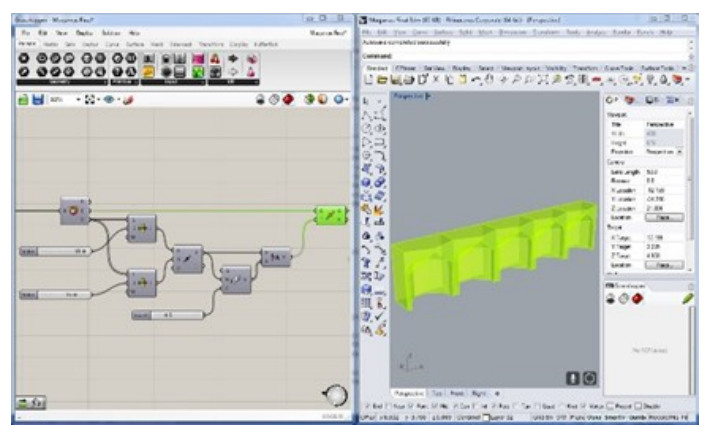

Figure 18. Arraying the first row of muqarnas - Generated by the author from grasshopper



Figure 19. Arraying top row and displacing it - Generated by the author from grasshopper

This process is then repeated to generate as many arraying rows as possible (Figure 20).

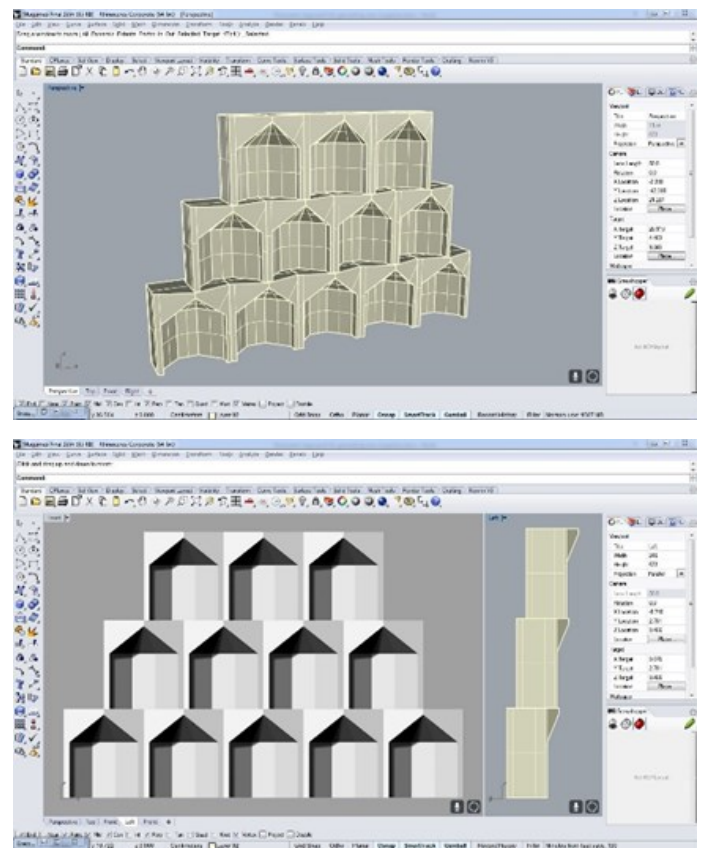

Figure 20. Generation of Muqarnas - Generated by the author from grasshopper

116 | Journal of Islamic Architecture, 5 (3) June 2019 
RESULT

As shown above, the process starts with the creation of a magic square pattern and translating it in Grasshopper to transform the mechanism into a parametric and algorithmic generative process. It resulted in the generation of a new form. Using this form parametrically leads to a consecutive supported semistructure element that could be named a parametric muqarnas

\section{DISCUSSION}

\section{DIGITALIZING THE PROCESS}

The research addressed the muqarnas specifically due to its uniqueness and complicated nature and its distinctive position in the decorations and ornaments of the Islamic Architecture.

Experiences relating to this historic element has been transferred and handled through the generations through trial and error, and innovation, however, there isn't a clear defined process.

\section{PARAMETRIC MUQARNAS}

The paper's main objective was to reformulate the muqarnas generation process, by using a parametric generative process to analyze the constituent units using the hypothesis of the relationship between the geometric patterns derived from the cosmological order and the muqarnas base units, and that's why magic squares were used.

\section{METHODOLOGY OF GENERATION}

The $3 \times 3$ Saturn magic square pattern used in the application is merely an example and a base to the hundreds of 2D geometric patterns that could be created following the methodology of generation mentioned above.

The choice of the 2D patterns used was based on comparison with basic geometrical art patterns of Islamic Architecture, although, not disregarding the creation of new patterns that hold the same characteristics of Islamic art patterns.

Furthermore, the $2 \mathrm{D}$ pattern would be given the $3^{\text {rd }}$ dimension and transformed into a $3 \mathrm{D}$ unit encompassing the muqarnas base unit.

\section{A STARTING POINT}

Finally, the form arraying process could take two paths, the first, a linear path with displacing upper rows that could be used as linear niches and alcoves. The second a radial array which would line the inside of constructed ceilings or domes. The paper addressed the first case for its simple structural form, and guaranteed a balanced outcome, with a purpose of creating a new idea to initiate innovations and trends in muqarnas generation

\section{CONCLUSION}

As discussed above, the research's objective was to formulate a parametric generative process for a new muqarnas. The methodology conceived in this paper could be used to generate several new designs of muqarnas forms based on Islamic architecture concepts relating to the cosmological order of the universe and its relation to the beautiful objective nature of geometry.

To conclude, (parametric design + hypothetical geometric patterns) in a linear or polar arraying direction produces a clearly defined muqarnas. To complement this research, future studies should be conducted addressing the examination of the structure identified, construction method, generating of new ceiling transformations of architectural spaces, and performing structural analysis on the generated form to test its structural limitations.

\section{REFERENCES}

[1] G. Necipoglu, "The Concept of Islamic Art: Inherited Discourses and New Approaches," J. Art Hist., vol. 6, no. June, pp. 57-75, 2012.

[2] S. S. Blair and J. M. Bloom, "The Mirage of Islamic Art: Reflections on the Study of an Unwieldy Field," Art Bull., vol. 85, no. 1, pp. 152 $-184,2003$.

[3] Y. Dold-Samplonius and S. Harmsen, "Muqarnas, Construction and Reconstruction," in Nexus V: Architecture and Mathematics, K. Williams and F. D. Cepeda, Eds. Florence: Kim Williams Books, 2004, pp. 69-77.

[4] Y. Korbendau, L'architecture sacrée de I'Islam. ACR, 1997.

[5] R. Krautheimer, Early Christian and Byzantine Architecture (The Yale University Press Pelican History of Art), 4th ed. Yale University Press, 1984.

[6] S. Skinner, Sacred geometry?: deciphering the code. Sterling, 2009.

[7] L. M. Dabbour, "Geometric proportions: The underlying structure of design process for Islamic geometric patterns," Front. Archit. Res., vol. 1, no. 4, pp. 380-391, 2012.

[8] Y. Abdullahi and M. R. Bin Embi, "Evolution of Islamic geometric patterns," Front. Archit. Res., vol. 2, no. 2, pp. 243-251, 2013.

[9] J. Ghiasvand, M. Akhtarkavan, and H. Akhtarkavan, "Adaptive Re-use of Islamic and Iranian Architecture's Elements," in WSEAS International Conference on CULTURAL HERITAGE AND TOURISM (CUHT'08), Heraklion, Crete Island, Greece, July 22-24, 2008, 2008, pp. 19-24.

[10] D. Swinford, "The Muqarnas: A Key Component of Islamic Architecture | Encyclopedia.com," Science and Its Times: Understanding the Social Significance of Scientific Discovery. 
2001.

[11] M. O. Djibril and R. O. H. Thami, "Islamic geometrical patterns indexing and classification using discrete symmetry groups," J. Comput. Cult. Herit., vol. 1, no. 2, pp. 1-14, Oct. 2008.

[12] Y. Dold-Samplonius and S. L. Harmsen, "Muqarnas: Construction and Reconstruction," in Architecture and Mathematics from Antiquity to the Future, Cham: Springer International Publishing, 2015, pp. 709-719.

[13] K. A. C. Creswell, A Short Account of Early Muslim Architecture: K. A. C. Creswell: Amazon.com: Books, 1st ed. Penguin Books, 1958.

[14] M. A. Yaghan, "A short on-line course on MUQARNAS," 2005. .

[15] E. J. Grube and G. Michell, Architecture of the Islamic world?]: its history and social meaning?]: with a complete survey of key monuments and 758 illustrations, 112 in colour. Thames and Hudson, 1995.

[16] N. Hamekasi, F. F. Samavati, and A. Nasri, "Interactive modeling of Muqarnas," Proc. Int. Symp. Comput. Aesthet. Graph. Vis. Imaging CAe '11, p. 129, 2011

[17] A. Tedeschi, F. Wirz, and S. Andreani, $A A D$, Algorithms-aided design]: parametric strategies using Grasshopper. .

[18] W. S. (William S. Andrews, Magic squares and cubes. Cosimo Classics, 2004.

[19] K. Critchlow, Islamic Patterns - An Analytical \& Cosmolgical Approach.pdf. Inner Traditions, 1999.

[20] J. Bourgoin, Arabic geometrical pattern and design. Dover Publications, 1973. 